\title{
Tibetan Spaniel
}

National Cancer Institute

\section{Source}

National Cancer Institute. Tibetan Spaniel. NCI Thesaurus. Code C53863.

The Tibetan Spaniel is a small dog that looks rather like a Pekingese, but with a slightly longer face, less profuse coat and no extra skin around the eyes. It has a plumed tail curled over his back, feathered pendent ears and soft, medium-length, flat coat. Height: 10 inches $(51 \mathrm{~cm}$.) Weight: 9-15 pounds (4.1-6.8 kg.) 